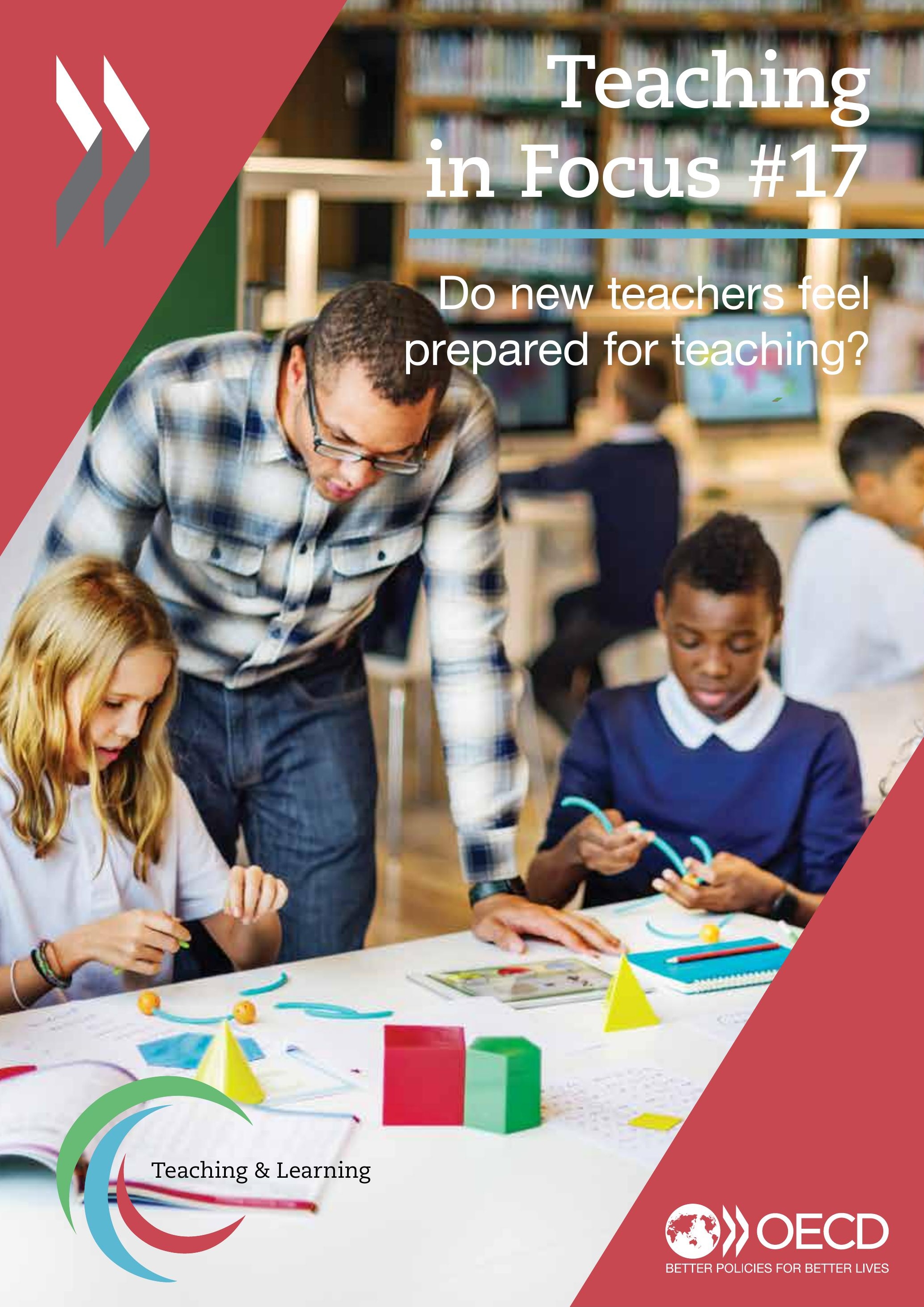




\section{Do new teachers feel prepared for teaching?}

- Across TALIS 2013 countries and economies, new teachers with a maximum of three years' work experience comprise, on average, $10 \%$ of the total teacher population.

- New teachers are more likely to feel prepared in the content of their subject field(s), rather than the pedagogy or classroom practice of their subject field(s). However, the levels of their perceived preparedness were lower than that of experienced teachers in all three domains.

- In nearly two-thirds of TALIS 2013 countries and economies, the largest difference in reported preparedness between new and experienced teachers was in classroom practice of the subject field(s) they teach, followed by the pedagogy of the subject field(s) they teach.

\section{What is TALIS?}

TALIS (Teaching and Learning International Survey) is the first international survey examining teaching and learning environments in schools. It asks teachers and school principals about their work, their schools and their classrooms. This cross-country analysis helps countries identify others facing similar challenges and learn about their policies.

TALIS 2013 focused on lower secondary education teachers and their principals. It sampled 200 schools in more than 30 countries and 20 teachers in each school. More information is available at: www.oecd.org/talis

The TALIS Initial Teacher Preparation study (ITP) is a new study involving eight countries - Australia, Japan, Korea, Netherlands, Norway, Saudi Arabia, United States and Wales that provides policy makers and practitioners with examples of effective and innovative policies to improve initial teacher preparation systems.

www.oecd.org/edu/school/talis-initial-teacher-preparation-study.htm.

It has been said that preparation is key to success and that, without preparation, the result is sure to be failure. This is particularly true for teachers entering the teaching profession. When new teachers start teaching, they often bring energy and enthusiasm into their classrooms. However, the first phase of their careers can be strenuous and stressful, as they have limited experience for coping with many new and challenging situations. It is unsurprising, then, that new teachers in most countries report lower levels of confidence than their more experienced peers (OECD, 2012). Some even experience burnout early in their careers and, in some countries, more than a third of new teachers leave the profession within the first five years (OECD, 2014a). A careful strategy is, therefore, needed to produce confident teachers and to support and develop them as learning professionals over the course of their careers. 


\section{Proportion of new teachers}

On average, new teachers with a maximum of three years' work experience comprise about $10 \%$ of the total teacher population across TALIS 2013 countries and economies. Italy (3\%), Portugal (1\%) and Spain (3\%) have the smallest proportion of new teachers across participating countries and economies. Singapore (30\%) has the biggest proportion of new teachers, followed by England (16\%). The relatively higher proportion of new teachers in some countries could reflect the existence of more successful policies to attract prospective teachers to the profession, possibly linked to the higher status of the profession or other incentives, general supply-demand issues, or other factors.

Table 1. Proportion of new and experienced teachers in TALIS 2013

Frequency and percentage of new and experienced teachers, as a percentage of total number of teachers reporting in TALIS 2013

\begin{tabular}{|c|c|c|c|c|c|c|c|c|c|}
\hline & \multicolumn{2}{|c|}{$\begin{array}{c}\text { New } \\
\text { teachers }\end{array}$} & \multicolumn{2}{|c|}{$\begin{array}{l}\text { Experienced } \\
\text { teachers }\end{array}$} & & \multicolumn{2}{|c|}{$\begin{array}{c}\text { New } \\
\text { teachers }\end{array}$} & \multicolumn{2}{|c|}{$\begin{array}{l}\text { Experienced } \\
\text { teachers }\end{array}$} \\
\hline & $\mathrm{n}$ & $\%$ & $\mathrm{n}$ & $\%$ & & $\mathrm{n}$ & $\%$ & $\mathrm{n}$ & $\%$ \\
\hline Abu Dhabi (UAE) & 215 & 8.9 & 2107 & 91.1 & Korea & 342 & 12.8 & 2498 & 87.2 \\
\hline Alberta (Canada) & 239 & 14.0 & 1503 & 86.0 & Latvia & 78 & 4.7 & 1934 & 95.3 \\
\hline Australia & 222 & 11.2 & 1791 & 88.8 & Malaysia & 368 & 12.6 & 2589 & 87.4 \\
\hline Brazil & 1158 & 10.8 & 10804 & 89.2 & Mexico & 253 & 10.7 & 2252 & 89.3 \\
\hline Bulgaria & 118 & 5.0 & 2445 & 95.0 & Netherlands & 218 & 12.2 & 1676 & 87.8 \\
\hline Chile & 233 & 16.2 & 1251 & 83.8 & New Zealand & 296 & 11.2 & 2358 & 88.8 \\
\hline Croatia & 377 & 12.9 & 2580 & 87.1 & Norway & 397 & 14.0 & 2500 & 86.0 \\
\hline Czech Republic & 297 & 9.3 & 2862 & 90.7 & Poland & 184 & 5.1 & 3473 & 94.9 \\
\hline Denmark & 136 & 8.6 & 1473 & 91.4 & Portugal & 32 & 1.1 & 3483 & 98.9 \\
\hline England (UK) & 395 & 16.3 & 2016 & 83.7 & Romania & 294 & 9.8 & 2938 & 90.2 \\
\hline Estonia & 203 & 6.9 & 2806 & 93.1 & Russian Federation & 402 & 11.5 & 3307 & 88.5 \\
\hline Finland & 292 & 10.4 & 2384 & 89.6 & Serbia & 349 & 11.1 & 3034 & 88.9 \\
\hline Flanders (Belgium) & 375 & 12.3 & 2660 & 87.7 & Shanghai (China) & 412 & 10.1 & 3470 & 89.9 \\
\hline France & 191 & 6.1 & 2766 & 93.9 & Singapore & 964 & 30.0 & 2112 & 70.0 \\
\hline Georgia & 110 & 5.8 & 1651 & 94.2 & Slovak Republic & 336 & 10.4 & 3099 & 89.6 \\
\hline Iceland & 153 & 11.2 & 1209 & 88.8 & Spain & 99 & 3.4 & 3205 & 96.6 \\
\hline Israel & 402 & 12.6 & 2894 & 87.4 & Sweden & 231 & 7.2 & 3032 & 92.8 \\
\hline Italy & 94 & 3.0 & 3207 & 97.0 & TALIS average & & 10.2 & & 89.8 \\
\hline Japan & 410 & 12.4 & 2984 & 87.6 & United States ${ }^{1}$ & 258 & 13.9 & 1655 & 86.1 \\
\hline
\end{tabular}

Note: 1. The data from the United States are located below the line in selected tables in this paper and are not included in the calculations for the international average. This is because the United States did not meet the international standards for participation rates.

For further information on TALIS 2013 documentation, instruments and methods, see the "TALIS Technical Report" (OECD, 2014b) and the TALIS

website (www. oecd.org/talis).

Source: OECD (2013), Teaching and Learning International Survey (TALIS): 2013 complete database,

http://stats.oecd. org/index.aspx?datasetcode=talis 2013\%20. 


\section{Feelings of preparedness of new vs experienced teachers}

These teachers were asked about their feelings of preparedness ("not at all", "somewhat", "well", and "very well") in three domains: content, pedagogy and classroom practice of the subject field(s) they teach. Figure 1 compares responses of new and experienced teachers in each domain. Overall, most teachers seem fairly confident. More than $80 \%$ of new teachers reported that they feel "well" or "very well" prepared in all three domains, and over $90 \%$ of experienced teachers did.

It is not surprising that experienced teachers reported significantly higher levels of preparedness than new teachers, but differences in reported levels of preparedness between new and experienced teachers display some interesting patterns across domains. New teachers are more likely to feel prepared in the content of the subject field(s) compared to the pedagogy or classroom practice of the subject field(s).

Figure 1. Feelings of preparedness of new vs experienced teachers

Percentage of new and experienced teachers reporting preparedness in content, pedagogy, and classroom practice of the subject(s) they teach

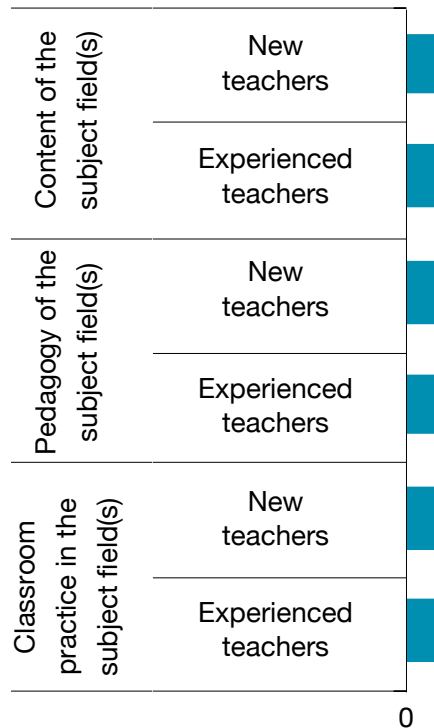

Very well

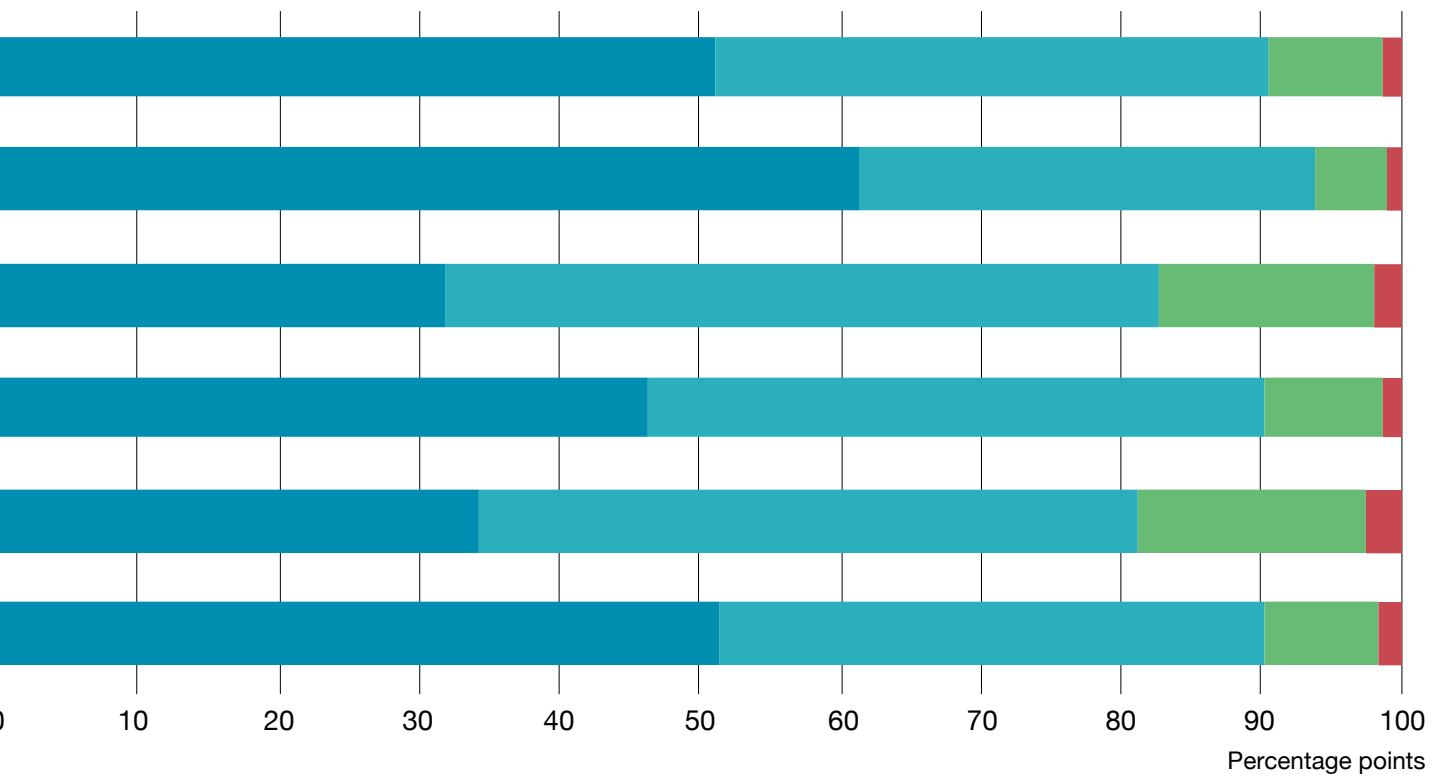

Well
Somewhat

Source: OECD (2013), Teaching and Learning International Survey (TALIS): 2013 complete database, http://stats. oecd. org/index.aspx?datasetcode=talis 2013\%20. 


\section{Gaps in feelings of preparedness between new and experienced teachers}

Figure 2 displays the differences, by domain, in percentage points between the proportion of new and experienced teachers who reported feeling "very well" prepared. It reveals the magnitude of the gaps between new and experienced teachers' preparedness in TALIS 2013 countries and economies. In countries and economies where gaps are positive, a higher share of experienced teachers reported being well prepared, while the opposite is true in countries and economies where gaps are negative. Wider gaps in countries between new and experienced teachers may indicate that more strategies and resources are needed to better prepare new teachers. In Finland, France, Georgia, Japan and Korea, the difference between new and experienced teachers is smaller than $10 \%$ or not significant in all areas, while the gap was larger than $20 \%$ in all three areas in Australia, Estonia and New Zealand, with statistically significant differences.

\section{Preparedness in content of the subject field(s)}

Both new and experienced teachers reported better preparedness in the content rather than the pedagogy and classroom practice of the subject field(s) they teach. More than $90 \%$ of both new and experienced teachers reported that they feel "well" or "very well" prepared in the content of their subject field(s). As shown in Figure 2, statistically significant differences between the two groups of teachers for the content knowledge domain are found in only 22 of the 37 TALIS 2013 countries and economies, whereas there are statistically significant differences in more than 32 countries and economies in the other two domains: pedagogical and practical knowledge to teach subjects. In 15 countries and economies, including France, Georgia, Italy and Korea, the difference between new and experienced teachers who reported feeling "very well" prepared in content knowledge was not statistically significant. Countries such as Australia and New Zealand had the largest gaps between the proportion of new and experienced teachers reporting high levels of preparedness in the content of their subject field(s), with statistically significant differences of 27 and 26 percentage points, respectively (See Figure 2).

\section{Preparedness in pedagogy of the subject field(s)}

In many participating countries and economies, the largest difference between new and experienced teachers was in the pedagogy of the subject field(s) they teach. Differences, for this domain, between new and experienced teachers were the largest in Israel (30 percentage points), Estonia (29 percentage points), Romania (27 percentage points) and Malaysia (21 percentage points). In contrast, differences between new and experienced teachers were only 6 percentage points in Finland, France and Japan. In Italy and Korea, no statistically significant differences were found. The magnitude of some of these differences suggest that, in some countries, new teachers may require more support to develop effective pedagogical strategies for teaching content than in others, possibly due to limited pre-service or in-service training. 
Figure 2. Gaps in feelings of preparedness between new and experienced teachers

Differences in percentage points between the proportion of new and experienced teachers who reported feeling "very well" prepared in content, pedagogy and classroom practice of the subject(s) they teach

\section{0}

35

30

25

20

10

5

0

$-5$

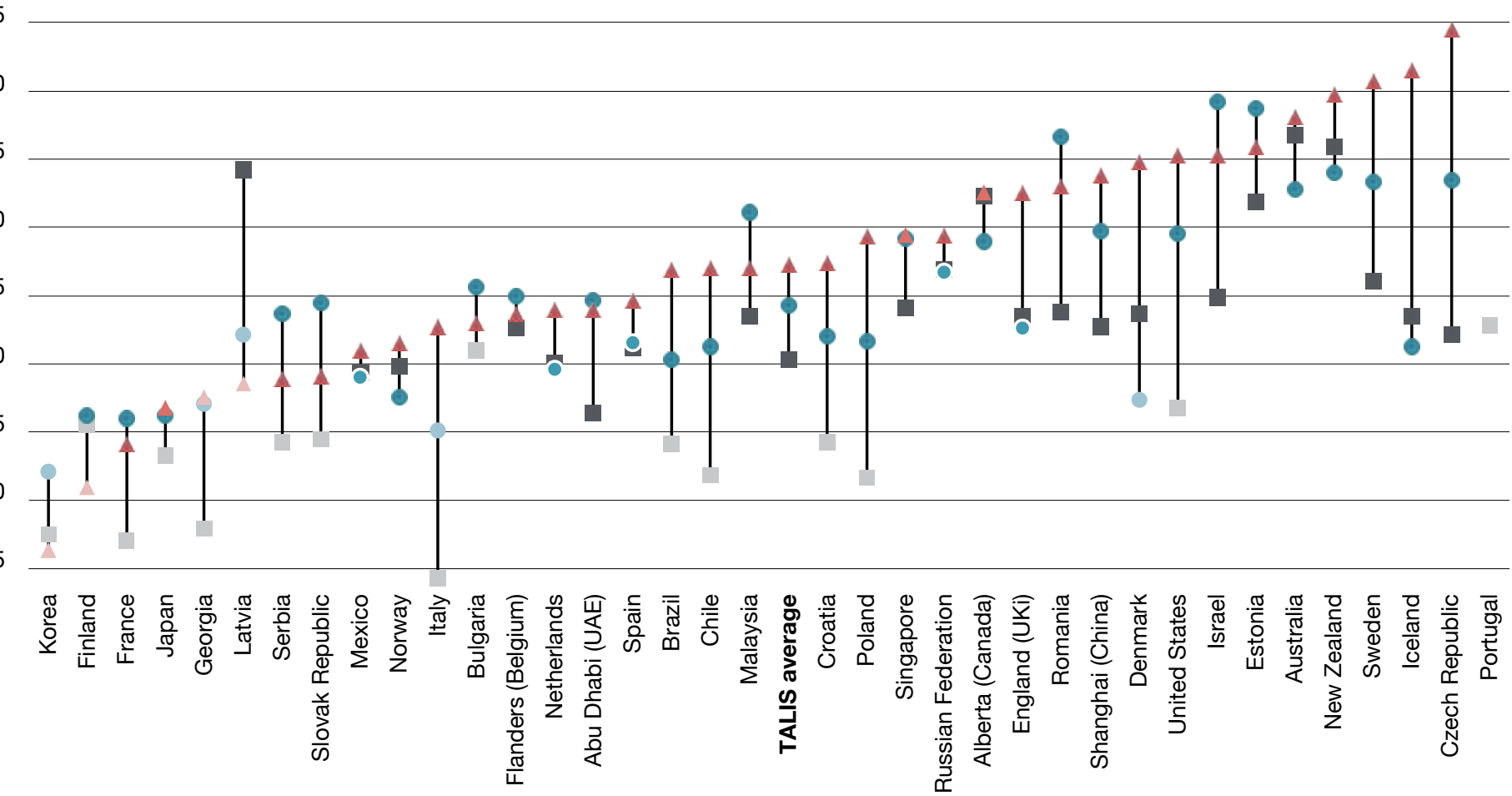

Content of the subject field(s)

- Pedgagogy of the subject field(s)

Classroom practice in the subject field(s)

Data are ranked in ascending order according to the differences in proportion of new and experienced teachers who reported feeling "very well" prepared in classroom practice in the subject field(s).

Notes:

1. Items for which the gaps are not statistically significant at $5 \%$ are presented in opaque colours in this figure.

2. This figure does not present the results when sampling variability of the estimate was too high for reporting with greater than $33.3 \%$ of coefficient of variation.

Source: OECD (2013), Teaching and Learning International Survey (TALIS): 2013 complete database,

http://stats.oecd.org/index.aspx?datasetcode=talis 2013\%20. 
Preparedness in classroom practice of the subject field(s)

In more than half of TALIS 2013 countries and economies, the largest difference in reported preparedness between new and experienced teachers was in classroom practice of the subject field(s) they teach. In countries such as the Czech Republic, Iceland and Sweden, the gaps between the proportion of new and experienced teachers feeling "very well" prepared in classroom practice in the subject field(s) were greater than 30 percentage points. However, in France and Japan, the differences between the groups were only 4 and 7 percentage points, respectively. In Finland and Korea, no statistical significant differences were found. These results may reflect prospective teachers' exposure to teaching as part of pre-service education, and/or different levels of support provided to new teachers as part of in-service training.

\section{The bottom line}

This analysis reveals that teacher education institutions in many countries and economies may have been over-emphasising content knowledge, rather than balancing other important types of teacher knowledge, such as pedagogical content knowledge, general pedagogical knowledge, or new knowledge emerging from educational science or a multidisciplinary field. Reforms in teacher education curriculum need to be conducted in line with evidence-based research in order to equip prospective teachers with sufficient pedagogical content knowledge and classroom practice, as well as content knowledge.

Systems that prioritise initial teacher preparation understand that a teacher's initial education can help lay the foundations for teaching quality. However, improving the quality of initial teacher preparation in order to create ready-made professionals is neither realistic nor desirable. Rather, providing the conditions in which teachers can continue to grow and develop as professional learners - from their first days in the classroom and throughout their careers - is an important step towards improving the quality of education. 
